Edmundo O'Gorman, El Diablo en la conquista, edición de Manuel Ramos Medina (México: Centro de Estudios de Historia de México-Carso, 2018).

\title{
Fernando CIARAMITARO
}

https://orcid.org/0000-0002-0299-7057

Universidad Autónoma de la Ciudad de México (México)

fernando.ciaramitaro@uacm.edu.mx

De manera admirable, Manuel Ramos ha rescatado un "proyecto inconcluso"1 de Edmundo O'Gorman (1906-1995): la historia del diablo en el Nuevo Mundo en los siglos XV-XVIII. Gracias a unos papeles custodiados desde los años 1950 por una exalumna de O'Gorman, sabemos ahora que el reconocido historiador y filósofo mexicano estuvo fascinado por el diablo, sus expresiones, la "dimensión esencial de lo histórico" y la muerte (p. 35-36). Este tema no ha dejado de atraer a jóvenes y no tan jóvenes, generación tras generación, en diferentes ramas del saber, el arte y la iconografía: como la literatura, el teatro, la pintura, el cine, la televisión, la música y, más recientemente, los cómics.

Pero todo empezó por la fe: el "demonio moderno" entró perentoriamente en la praxis y el alegato sociorreligioso de Occidente en los siglos XII y xııI y desde entonces jamás se ha marchado. ${ }^{2}$ Mientras que para teólogos y creyentes Dios es el ser por antonomasia, el vulgo considera al diablo metáfora del mal humano: feo, monstruoso, grotesco, infame, la perversión que habita y atormenta el corazón de hombres y mujeres. ${ }^{3}$ Precisamente, nos percatamos de que también O'Gorman se interesó en el demonio, en una fase intelectual de su vida todavía en construcción. Y si la hipótesis de Ramos, de que un posible diablo se manifestó en su casa para asustarlo e intimarlo a no seguir en su trabajo, parece fantástica, es cierto que resulta necesario estudiar este "perdido" tratado de la larga trayectoria del erudito

${ }^{1}$ La fórmula "proyecto inconcluso" es del editor (p. 11).

${ }^{2}$ Robert Muchembled, Historia del diablo, siglos XII-XX (México: Fondo de Cultura Económica, 2002): 9, 19-47.

${ }^{3}$ Sobre estas consideraciones generales acerca del diablo cristiano, véase mi reciente ensayo: "El demonio de las brujas y la Inquisición de México: María Valenzuela, Felipa de Santiago de Canchola, la mulata María y María de Angulo", Revista de El Colegio de San Luis, v. 10, n. 21 (2020). 
mexicano. O'Gorman tuvo inicialmente una formación jurídica, se tituló en 1928 en la Escuela Libre de Derecho ${ }^{4}$ y practicó la abogacía durante una década; ${ }^{5}$ en 1938 dejó los expedientes judiciales para entrar como subdirector al AGN de México ${ }^{6}$ y obtener, diez años después, su maestría en Filosofía. ${ }^{7}$ En el ínterin ya había impartido docencia y había publicado su primer trabajo histórico (1937) $;^{8}$ un año después vio la luz su primer artículo en el Boletín del Archivo General de la Nación, sobre una solicitud de encomienda de indios de los pueblos Ayacastla y Ometepec, de Gonzalo Hernández de Herrera; ${ }^{9}$ en 1940 compuso su primer prólogo a la edición de la Historia natural y moral de las Indias, de Joseph de Acosta (15401600), ${ }^{10}$ testimonio imprescindible para cualquier estudio sobre el jesuita y la historia indiana del siglo Xvi; en 1941 escribió acerca de un proceso inquisitorial contra una india curandera, confrontándose con supersticiones y "perversos" maleficios. ${ }^{11}$ Desde entonces leía con entusiasmo y trabajaba en la búsqueda de fuentes para su estudio sobre el ángel caído en el Nuevo Mundo.

Presumiblemente, su labor se desarrolló en dos partes: para la primera anotó un registro manuscrito de las obras que examinaría, con un listado de dos páginas y 96 fichas de fuentes bibliográficas y documentales consultadas; para la segunda redactó un inédito prólogo, fechado en el otoño de 1940, y cimentó el andamiaje de la misma pesquisa, con la transcripción de sus expedientes, en 194 páginas, entre hojas sueltas, mecanografiadas o escritas de

${ }^{4}$ Véase Eugenia Meyer, Imprevisibles historias. En torno a la obra y legado de Edmundo O’Gorman (México: Fondo de Cultura Económica; México: Universidad Nacional Autónoma de México, 2009), 11. La monografía de Mayer es imprescindible para conocer la obra de O'Gorman.

5 Jorge Alberto Manrique, "Edmundo O’Gorman, 1906-1995”, Anales del Instituto de Investigaciones Estéticas, v. 17, n. 67 (1995): 195.

${ }^{6}$ Véanse AGN, Boletín del Archivo General de la Nación, v. 23, n. 2 (1952); Ernesto de la Torre Villar, “El Dr. Edmundo O’Gorman. Su separación del Archivo”, Boletín del Archivo General de la Nación, v. 4, n. 6 (1995-1996).

${ }^{7}$ El doctorado lo obtuvo en 1951, en la Facultad de Filosofía y Letras de la UnAm.

${ }^{8}$ Edmundo O'Gorman, Breve historia de las divisiones territoriales. Aportación a la historia de la geografía de México (México: Polis, 1937), reeditado más veces. Quien escribe ha leído la quinta edición: Historia de las divisiones territoriales de México (México: Porrúa, 1979).

${ }^{9}$ Edmundo O’Gorman, “Información sobre solicitud de encomiendas, 1549”, Boletín del Archivo General de la Nación, v. IX, n. 1 (1938).

${ }^{10}$ José de Acosta, Historia natural y moral de las Indias (México: Fondo de Cultura Económica, 1940). En 1962 O’Gorman publicó una edición revisada.

${ }^{11}$ Edmundo O'Gorman, "Proceso inquisitorial contra una india curandera, 1538”, Boletín del Archivo General de la Nación, v. XII, n. 2 (1941). 
su puño. O'Gorman se dio a la tarea de analizar fuentes primarias, como las de los grandes cronistas del primer siglo de la conquista, entre ellos Hernán Cortés y Joseph de Acosta, así como expedientes resguardados en el AGN.

En palabras del autor, estudiar al diablo es una cuestión de "alto interés humano" (p. 36), una operación compleja y turbadora del historiar, porque, al fin y al cabo, ser historiador comporta penetrar "en las regiones desconocidas de un mundo que hace señas a través de los textos y de los monumentos" (p. 35). La misma inquietud - subraya O'Gorman - que tuvo el poeta florentino Dante Aligheri (1265-1321), cuando se aprestó a iniciar su viaje hacia el infierno: el pasado está lleno de muertos, muchos de ellos infernales, verdaderos discípulos del demonio. Parafraseando a Leopold von Ranke, afirma que el escritor no debe quedarse en los armazones metodológicos, sino sacudir el mito de los hechos "como realmente fueron" a través de una lectura personal, lúcida y crítica. Este es el oficio del historiador y el relato histórico es la expresión de la correlación que establece el vivo con los difuntos.

Ramos reprodujo los vestigios de esta abandonada investigación en seis apartados: "Al amigo lector", "Transcripciones", "Fuentes indianas", "Reproducción de textos originales", "Texto de las fichas", "Reproducción de las fichas". En las dos secciones de "reproducción" se encuentran las fotografías de los mecanografiados, las notas manuales y las fichas, estas últimas todas de su puño y letra. La sección de las fuentes indianas es un índice o lista de 44 entradas que a O'Gorman habría servido de guía para las reseñas recolectadas.

El primer apartado es una especie de corta introducción: el mencionado prólogo dedicado al lector (dos páginas). Mientras que, en el segundo y el quinto, también transcritos por Ramos y acompañados por algunas breves anotaciones ogormanianas, se alistan referencias documentales y citas de algunos clásicos de la literatura y la historiografía universales, sin orden cronológico. Estas fuentes literarias, manualísticas o tratadísticas de los siglos XIII-XVII, completas, se resumen en el cuadro que sigue.

REFERENCIAS EMPLEADAS POR E. O'GORMAN EN SU INVESTIGACIÓN PARA EL DIABLO EN LA CONQUISTA

\begin{tabular}{ll}
\hline \multicolumn{1}{c}{ Autores } & \multicolumn{1}{c}{ Obras } \\
\hline Dante Aligheri (1265-1321) & La divina commedia \\
Geoffrey Chaucer $(c .1340-1400)$ & The Canterbury Tales \\
Cristóbal Colón (1451-1506) & Diarios y cartas \\
Hernán Cortés (1485-1547) & Cartas de relación y otros escritos
\end{tabular}




\begin{tabular}{|c|c|}
\hline Autores & Obras \\
\hline Pedro Mártir de Anglería (1457-1526) & Décadas del Nuevo Mundo \\
\hline $\begin{array}{l}\text { Francisco de Jerez o Francisco López } \\
\text { de Xerez }(c .1497-1565)\end{array}$ & $\begin{array}{l}\text { Verdadera relación de la conquista } \\
\text { del Perú y provincia del Cuzco }\end{array}$ \\
\hline Joseph de Acosta (1540-1600) & Historia natural y moral de las Indias \\
\hline $\begin{array}{l}\text { Gonzalo Fernández de Oviedo } \\
\quad(1478-1557)\end{array}$ & $\begin{array}{l}\text { Sumario de la natural historia de las } \\
\text { Indias }\end{array}$ \\
\hline $\begin{array}{l}\text { Bartolomé de las Casas } \\
\quad(1474 \text { o } 1484-1566)\end{array}$ & $\begin{array}{l}\text { Apologética historia sumaria } \\
\text { Historia de las Indias }\end{array}$ \\
\hline Fernando de Valdés (1483-1568) & Instrucciones al Santo Oficio \\
\hline $\begin{array}{l}\text { Francisco López de Gómara } \\
\quad(1511-1572)\end{array}$ & $\begin{array}{l}\text { Historia general de las Indias, Historia } \\
\text { de la conquista de México y Vida de } \\
\text { Hernán Cortés }\end{array}$ \\
\hline $\begin{array}{l}\text { Bernal Díaz del Castillo } \\
\quad \text { (1495 o 1496-1584) }\end{array}$ & $\begin{array}{l}\text { Historia verdadera de la conquista de la } \\
\quad \text { Nueva España }\end{array}$ \\
\hline $\begin{array}{l}\text { Bernardino de Sahagún } \\
\quad \text { (c. 1499-1590) }\end{array}$ & $\begin{array}{l}\text { Historia general de las cosas de Nueva } \\
\quad \text { España }\end{array}$ \\
\hline Pedro Cieza de León (1520-1554) & Crónica del Perú \\
\hline Diego de Landa (1524-1579) & Relación de las cosas de Yucatán \\
\hline Juan Suárez de Peralta (1541-1613) & $\begin{array}{l}\text { Tratado del descubrimiento de las } \\
\quad \text { Yndias y su conquista }\end{array}$ \\
\hline $\begin{array}{l}\text { Francisco Cervantes de Salazar (entre } \\
\qquad 1513 \text { y } 1518-1575 \text { ) }\end{array}$ & Crónica de la Nueva España [...] \\
\hline Jerónimo de Mendieta (1525-1604) & Historia eclesiástica indiana \\
\hline Francisco de Aguilar (1479-1571) & $\begin{array}{l}\text { Relación breve de la conquista de la } \\
\quad \text { Nueva España }\end{array}$ \\
\hline $\begin{array}{l}\text { Toribio de Benavente Motolinía } \\
\quad \text { (c. 1482-1569) }\end{array}$ & $\begin{array}{l}\text { Historia de los indios de la Nueva } \\
\quad \text { España }\end{array}$ \\
\hline $\begin{array}{l}\text { Alfonso de la Mota y Escobar } \\
\quad(1546-1625)\end{array}$ & $\begin{array}{l}\text { Descripción geográfica de los Reinos } \\
\text { de Nueva Galicia, Nueva Vizcaya } \\
\text { y Nuevo León }\end{array}$ \\
\hline $\begin{array}{l}\text { Alonso de la Peña Montenegro (1596- } \\
\text { 1687) }\end{array}$ & Itinerario para párrocos de indios \\
\hline
\end{tabular}

FUENTE: elaboración propia a partir del libro reseñado. 
Luego -siempre en los apartados de transcripción- se observa un abanico de fuentes diversas: datos acerca del Fuero real de Castilla, una cédula de Carlos V, bulas papales, un bando sobre campanas, edictos arzobispales, documentos inquisitoriales, procesos de indios idólatras, manuales, noticias y relaciones de triunfos, comentarios sobre imágenes y pinturas, autos sacramentales, descripciones geográficas, rituales de los naturales, itinerarios de la armada, ordenanzas, relaciones y solicitudes de servicios, documentos de los concilios provinciales mexicanos y del tridentino y un largo etcétera.

O'Gorman también recurre, en repetidas ocasiones, a la Colección de documentos para la historia de México (1858) del historiador, filólogo y editor mexicano Joaquín García Icazbalceta (1825-1894). Mientras que sus lecturas especializadas sobre la historia del diablo son sólo dos monografías, hoy poco citadas: una del periodista, helenista y traductor madrileño Rafael Urbano-García (1870-1924); otra del historiador y teólogo francés Joseph Turmel (1853-1943). ${ }^{12}$

Gracias a sus bosquejos, logramos entender que O'Gorman estuvo interesado en la sinonimia concebida por los cronistas y oficiales de la monarquía católica entre "demonios" y dioses (o "ídolos") de los naturales americanos. A través de sus glosas, puede leerse una precisa interpretación mesiánica de la conquista y la colonización de las Américas, realizadas por voluntad divina (p. 49, 111, 167, 170, 192, 194-195). Desde la temática del demonio, O'Gorman se inserta también en el debate historiográfico actual sobre ideología, mesianismo y edad dorada del siglo XVI: ante un proceso iniciado en la segunda mitad de la centuria, por el que se impone un nuevo modo gubernamental, basado en una mayor presión tributaria y el reforzamiento de la burocracia, y en el marco de una transformación socioeconómica fruto del acceso de Nueva España a los circuitos comerciales internacionales, se desencadenó un mesianismo universalista y providencialista que, frente a la disquisición histórica en clave apocalíptica y el palpable fracaso de una comunidad utópica de monjes e indios, ideó una mítica e idílica edad dorada que se habría desenvuelto a lo largo de los primeros decenios de la centuria, paralelamente a la marcha de la evangelización (p. 80-81). ${ }^{13}$

${ }^{12}$ Rafael Urbano, El diablo, su vida y su poder (toda su historia y vicisitudes) (Madrid: Biblioteca del Más Allá, 1922); Joseph Turmel, Histoire du diable (París: Rieder, 1931).

${ }^{13}$ En esa línea véase, por ejemplo, Antonio Rubial y María Teresa Suárez Molina, "La construcción de una Iglesia indiana. Las imágenes de su edad dorada”, en Los pinceles de la 
En la academia mexicana existe una larga y sólida tradición de saberes acerca de estos temas: las visiones del más allá, las supersticiones, el mesianismo, las apariciones y la correspondiente disertación antisupersticiosa, las presencias demoniacas. Entre los estudios más recientes quiero recordar los de Esther Cohen (2003), Antonio Rubial García y Doris Bieñko de Peralta (2011), Alberto Ortiz (2012), Claudia Carranza Vera (2013), Lourdes Somohano (2013) y Gisela von Wobeser (2016), entre otros. ${ }^{14} \mathrm{~A}$ través de metodologías, documentos y enfoques no siempre iguales, los citados investigadores, de ahora en adelante, tendrán que confrontarse con los rescatados apuntes de O'Gorman, sus posibles elucidaciones y las numerosas preguntas incontestadas que generan al leedor.

A través de la lectura del boceto de El Diablo en la conquista, queda patente cómo el lento proceso de aculturación generó en el Nuevo Mundo algunas fisonomías ceñidas, un universo de creencias y conductas que conllevaron una identificación del nativo con el demonio. En la pluma ogormaniana se percibe un diablo diferente, nuevo, amerindio, con raíces aborígenes, un peligroso satanás ídolo, que genera temor y miedo en la mirada del español. Una pura contingencia que debe ser humillada con la fuerza y la violencia. Como ha recordado Walter D. Mignolo, ${ }^{15}$ la tesis de O'Gorman sobre la "invención de América" ${ }^{16}$ y el universalismo de la cultura occidental reveló no sólo que la idea de descubrimiento es una "interpretación imperial", sino también que el Nuevo Mundo, como extremo occidental, tiene sus raíces en la cosmología cristiana. Es desde Occidente que se conceptualiza y clasifica al resto del mundo: es decir, la modernidad es la autodescripción del papel de Europa en la historia, más que un proceso histórico ontológico. ${ }^{17}$ O'Gorman, en sus libradas consideraciones sobre Motolinía, reitera esta verdad: no obstante el "aliento optimista de la propagación de la fe", el franciscano no dejaba de ser "imperialista" (p. 197).

historia. El origen del reino de la Nueva España, 1680-1750, catálogo de la exposición (México: Instituto Nacional de Bellas Artes, Museo Nacional de Arte, 1999), 144-145, 151.

${ }^{14}$ Sobre estas cuestiones temáticas y metodológicas remito a mi reciente trabajo ya citado: Ciaramitaro, "El demonio de las brujas".

15 Walter D. Mignolo, The Idea of Latin America (Malden-Oxford-Carlton: Blackwell Publishing, 2005), 84-85.

${ }^{16}$ La referencia es al clásico ogormaniano: La invención de América. El universalismo de la cultura de Occidente (México-Buenos Aires: Fondo de Cultura Económica, 1958).

${ }^{17}$ Sigo aquí algunas acertadas consideraciones de Corrado Giarratana, "Il ser americano nell'interpretazione di O’Gorman”, en Giancarlo Magnano San Lio y Luigi Ingaliso, ed., Antropologia e potere. Modelli scientifici, filosofici e filologici dell'acculturazione tra Ottocento e Novecento (Soveria Mannelli: Rubbettino, 2021). 
El O’Gorman redescubierto por Manuel Ramos ya no ignora el papel del indio en el análisis del proceso de aculturación, asimilación o rechazo, sino que relativiza su existencia y sus sufrimientos. Sin duda alguna, O'Gorman es precursor de Tzvetan Todorov, que inesperadamente pretendió ignorar el valor real de la propuesta del pensador mexicano, tratando de hacer pasar como simple historia de los "conceptos" geográficos su gran "invención" de América. ${ }^{18}$ Los otros, que han sido llamados "indios", tienen dos rasgos principales, el de la "generosidad" y el de la "cobardía". Esto refleja un sentimiento de superioridad que genera un "comportamiento proteccionista" de los europeos. Las actitudes de quienes se sienten conquistadores dependen de la forma en que los demás se perciban a sí mismos y esta forma de ver y juzgar es totalmente ambigua. A menudo, los indios son vistos como "diferentes" y diabólicos. Ellos se colocan, en la percepción del europeo, en términos de jerarquía: superioridad o inferioridad. Todorov dice que son físicamente desnudos y privados de cualquier identidad cultural: se caracterizan, de alguna manera, por la falta de costumbres, rituales, religión. Sin lengua, los indios también se revelan desprovistos de leyes y religión; y si tienen una cultura material, ella no llama la atención del observador ibérico. ${ }^{19}$

Los esfuerzos intelectuales por imaginar al otro demoniaco disfrazan formas de colonización que han ayudado a repensar la dimensión discursiva de la experiencia imperial (y poscolonial) y, como ha subrayado Álvaro Matute ${ }^{20}$ son apasionada defensa de la libertad en el campo de la historia, que ha encontrado en O'Gorman una voz fuerte para el amparo de cualquier faena intelectual. Y si los especialistas han asegurado que el corpus del pensamiento ogormaniano acerca del quehacer del historiador apareció entre 1942 y $1958,{ }^{21}$ tal vez ahora, a la luz del rescate realizado por Ramos, habría que retrodatar este corte temporal al año 1940 y considerar la pesquisa no acabada de O’Gorman — pero pensada de manera cabal— sobre el demonio en las Indias.

18 Tzvetan Todorov, La conquista dell'America. Il problema dell' “ altro” (Turín: Einaudi, 1992. Primera edición: París, 1982), 313. Acerca de esta idea, véase Giarratana, "Il ser americano”.

19 Todorov, La conquista dell'America. Véase también: Fernando Ciaramitaro, "La aculturación nell'America ispanica. Modelli e interpretazioni nel xxi secolo", en Giancarlo Magnano San Lio y Luigi Ingaliso, ed., Antropologia e potere, 2021.

20 Álvaro Matute Aguirre, “Introduzione”, en Edmundo O'Gorman, Historiologia. Teoria e pratica, ed. de Giuseppe Bentivegna (Acireale-Roma: Bonanno, 2017).

${ }^{21}$ Los extremos temporales serían Fundamentos de la historia de América (México: Imprenta Universitaria, 1942) y la ya citada La invención de América (1958). 


\section{Bibliografía}

Acosta, José de. Historia natural y moral de las Indias. México: Fondo de Cultura Económica, 1940.

AGN. Boletín del Archivo General de la Nación, v. 23, n. 2 (1952): 131-138.

Ciaramitaro, Fernando. "La aculturación nell'America ispanica. Modelli e interpretazioni nel xxi secolo." En Antropologia e potere. Modelli scientifici, filosofici e filologici dell'acculturazione tra Ottocento e Novecento. Ed. de Giancarlo Magnano San Lio y Luigi Ingaliso, 151-170. Soveria Mannelli: Rubbettino, 2021.

Ciaramitaro, Fernando. "El demonio de las brujas y la Inquisición de México: María Valenzuela, Felipa de Santiago de Canchola, la mulata María y María de Angulo." Revista de El Colegio de San Luis, v. 10, n. 21 (2020): 1-48.

Giarratana, Corrado. "Il ser americano nell'interpretazione di O'Gorman." En Antropologia e potere. Modelli scientifici, filosofici e filologici dell'acculturazione tra Ottocento e Novecento. Ed. de Giancarlo Magnano San Lio y Luigi Ingaliso, 139150. Soveria Mannelli: Rubbettino, 2021.

Manrique, Jorge Alberto. “Edmundo O'Gorman, 1906-1995.” Anales del Instituto de Investigaciones Estéticas, v. 17, n. 67 (1995).

Matute Aguirre, Álvaro. “Introduzione.” En Edmundo O'Gorman, Historiologia. Teoria e pratica. Ed. de Giuseppe Bentivegna, 31-52. Acireale-Roma: Bonanno, 2017.

Meyer, Eugenia. Imprevisibles historias. En torno a la obra y legado de Edmundo O'Gorman. México: Fondo de Cultura Económica; México: Universidad Nacional Autónoma de México, 2009.

Mignolo, Walter D. The Idea of Latin America. Malden-Oxford-Carlton: Blackwell Publishing, 2005.

Muchembled, Robert. Historia del diablo, siglos XII-XX. México: Fondo de Cultura Económica, 2002.

O'Gorman, Edmundo. Historia de las divisiones territoriales de México. México: Porrúa, 1979.

O'Gorman, Edmundo. La invención de América. El universalismo de la cultura de Occidente. México-Buenos Aires: Fondo de Cultura Económica, 1958.

O'Gorman, Edmundo. Fundamentos de la historia de América. México: Imprenta Universitaria, 1942.

O'Gorman, Edmundo. "Proceso inquisitorial contra una india curandera, 1538." Boletín del Archivo General de la Nación, v. XII, n. 2 (1941): 7-14.

O'Gorman, Edmundo. "Información sobre solicitud de encomiendas, 1549." Boletín del Archivo General de la Nación, v. Ix, n. 1 (1938): 64-86.

Rubial, Antonio, y María Teresa Suárez Molina. "La construcción de una Iglesia indiana. Las imágenes de su edad dorada." En Los pinceles de la historia. El ori- 
gen del reino de la Nueva España, 1680-1750, catálogo de la exposición. México: Instituto Nacional de Bellas Artes, Museo Nacional de Arte, 1999.

Todorov, Tzvetan. La conquista dell'America. Il problema dell'“altro”. Turín: Einaudi, 1992.

Torre Villar, Ernesto de la. "El Dr. Edmundo O'Gorman. Su separación del Archivo." Boletín del Archivo General de la Nación, v. 4, n. 6 (1995-1996): 129-138.

Turmel, Joseph. Histoire du diable. París: Rieder, 1931.

Urbano, Rafael. El diablo, su vida y su poder (toda su historia y vicisitudes). Madrid: Biblioteca del Más Allá, 1922. 